\title{
LETTER FROM THE DIRECTOR
}

I am proud to present you with the latest volume of Policy Perspectives, the Trachtenberg School of Public Policy \& Public Administration's superb student journal. The journal is the product of our entire community - faculty, students and alumni - and illustrates our commitment to advancing effective governance through public service education.

In this 24th volume, our students tackle an array of policy questions that are front and center in people's everyday lives, from health care to privacy. Eric Flanagan, MPA '17, studied all-payer rate setting as a method for creating a more efficient health care system, while David Walrath, MPP '17, conducted an economic analysis of privacy and information disclosure rules outlined in the Graham-Leach-Bliley Act.

Authors addressed challenging issues at local, national and international levels.

David Meni, MPP '17, investigated transitional housing policy right here in Washington, D.C. Meanwhile, Jennifer Lewis, MPP '17, examined gaps in the Earned Income Tax Credit. And Claire Viall, MPP '18, assessed the role of international influence on laws concerning abortion access in the Republic of Ireland and Northern Ireland.

This volume also includes timely commentary on education policy. Maxwell Tingle, MPA '17, considered whether subsidizing test preparation for standardized tests could serve as an alternative to affirmative action policies in university admissions. Callie McLean, MPA '17, and Lily Robin, MPP '17, collaborated to explore advocacy-oriented think tanks and the role of organizational mission in shaping education policy research.

The contents of this volume represented team efforts. Each article was extensively reviewed by our student editors and faculty reviewers. The authors enthusiastically underwent multiple rounds of revisions to ensure their conclusions were supported by high-quality data and rigorous analyses.

Our students also published a great number of policy briefs on the journal's online blog, Brief Policy Perspectives. Launched in 2015, the blog enables student authors to explore a variety of topics, often as debates are playing out in policy circles around the world. Indeed, many of the articles published in the past year reflect the major policy questions addressed in 2016, including challenges in rural electrification, equity in marijuana legalization, and the consequences of federal hiring freezes. 